\title{
A Combined Model of Blockchain, Price Intelligence and IoT for Reducing the Corruption and Poverty
}

\author{
Md. Akhtaruzzaman, S. Rayhan Kabir, Rafita Haque, Muhammad Jafar Sadeq, Arpita \\ Chowdhury \\ Department of Computer Science and Engineering, Asian University of Bangladesh
}

\begin{abstract}
Corruption of price hike is common and one of the major issues in the third world as well as in developing countries. Corruption and price hike issues are correlated with one another. A number of recent studies have been examined to establish the relationship between corruption and poverty. The people of low and middle-income countries cannot take proper medical treatment and buy nutritional food due to price hike and corruption. As a result, every year, many children and poor people have been suffering and dying from malnutrition. Blockchain is a leading technology which is prohibitive to data manipulation and an open distributed computation system where data transactions occur between two parties efficiently. Price Intelligence technology is used for price monitoring at the market level. This study presents a technological model where we have used blockchain, price intelligence and IoT approaches for monitoring the price transaction in the medical, banking and educational areas. This proposed model represents a technological architecture where different people and organizations are connected to the cloud through the internet and money transactions happened through blockchain approach. As a result, people of differing abilities and resources can detect the price hike and corruption and poor people can get priority for better service. Finally, we have suggested the potential impact of the proposed model and have explained how poor people can get better service by using this model.
\end{abstract}

Keywords: Sustainable Development, Management Information System (MIS), Organizational Communication, Price Intelligence, Blockchain based IoT (BIoT).

\section{Introduction}

Corruption not only hampers administrative activities but also damages the interest of the poor and damages a country in various ways, including its image (Dimant and Tosato, 2017). Corruption is a global threat; it affects both developed and developing countries (Unver and Koyuncu, 2016). It usually has a devastating effect on low and middle-income countries (LMIC) as well as under-developed countries, especially Asia and Africa, especially those living in the poorer rural areas of the developing world (Yunan and Andini, 2018; Awojobi and Nathaniel, 2014). A recent study has found that rural officials have the highest impact on the corruption in a village (Zheng and Liao, 2018). This study has used system dynamic methods to qualitatively analyze the factors affecting the corruption in rural areas. In urban areas, the ratio of poor living is increasing (Dubey and Tiwari, 2018). Price hike is another major issue in our daily life which affects economic growth. People of the low and middle-income families cannot take proper treatment, education and afford nutritious foods for high price and corruption problems (Andrade et al., 2018; Omoniyi, 2018).

In today's era, information technology (IT) makes an effective contribution to growing the socio-economic development in countries around the world (Palvia et al., 2018). The comprehensive adoption and integration of IT has reduced transaction costs, improved service distribution, built new jobs, produced new revenue flow and helped conserve foods (Katz, 2017). IT also has transformed the way businesses and governments act, and the nature of human interactions and communications. The new technologies and innovative usages of Computer Science have created enormous opportunities and pose daunting challenges to reducing poverty and hunger 
(Food and Agriculture Organization [FAO] of The United Nations, 2018). In recent years, Blockchain has been becoming a buzzword. Blockchain technology flowed in the financial sectors enabling crypto currencies such as Bitcoin, Litecoin, Namecoin etc. (Phillip, Chan and Peiris, 2017). This gives hopes that there are prospects that blockchain will secure the integrity and root out corruption in governance (Third et al., 2018; Jalakas, 2018). However, blockchain is not yet well-known or understood by most stakeholders but international organizations or companies are appropriate to bringing all stakeholders including the government and business together to think of a powerful strategy rule on the blockchain utilization. (Kim and Kang, 2017).

Blockchain is a method which maintains the digital records that are shared among the shareholders or participants (Risius and Spohrer, 2017). This technology deals with every transaction of the parties involved by dealing with the period and content of each transaction (Mendling et al., 2018). If a transaction holds fraud or fake information due to corruption, it is not validated due to the unity protocol (Santiso, 2018). Therefore, the transaction cannot take place. As such, the blockchain method can be a workable tool to find the corruption through having a transparent view on every transaction (Gupta and Sadoghi, 2018). The transaction and working process of blockchain technology have been illustrated in Figure 1.

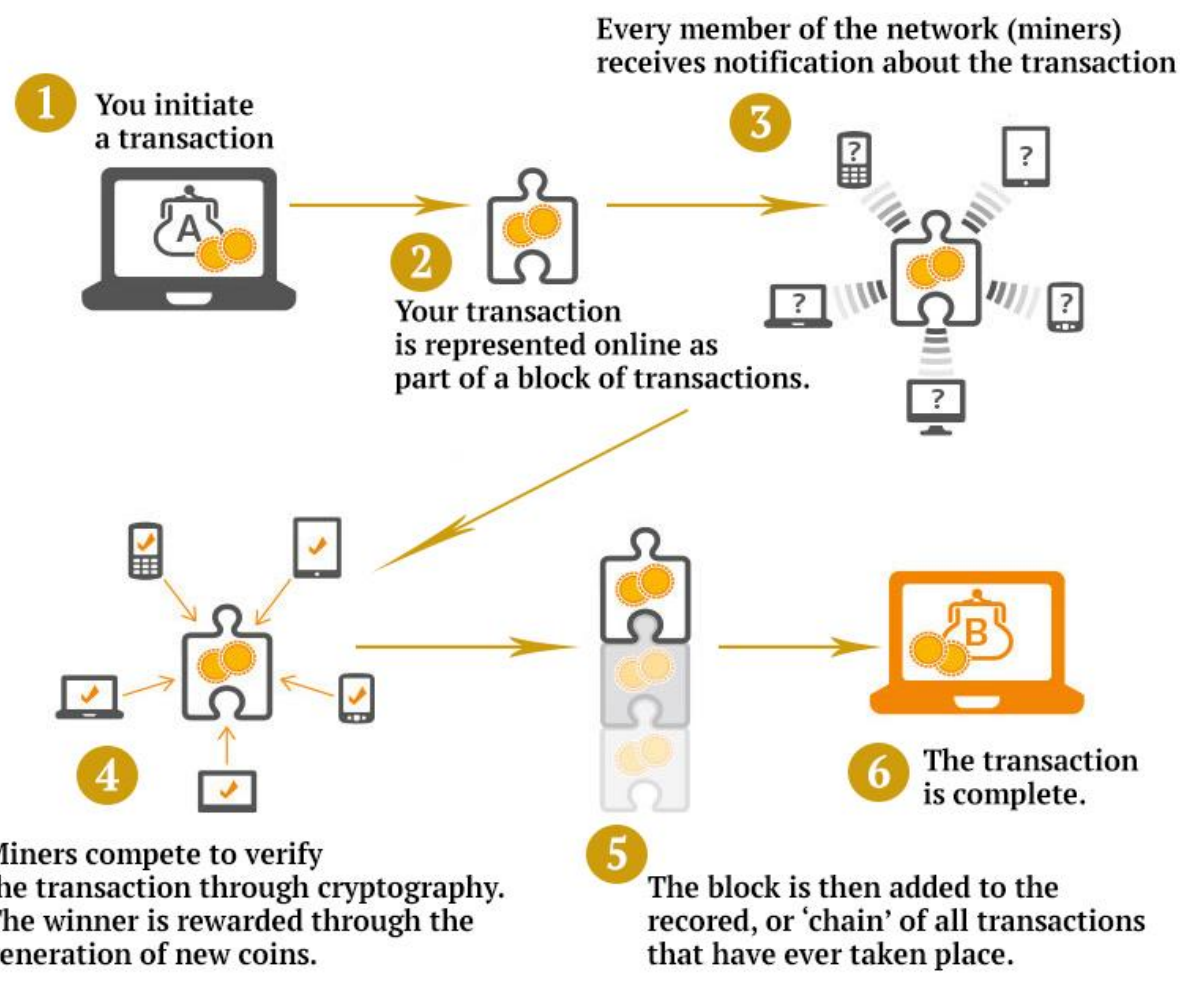

Figure 1: Data or information transaction process of blockchain technology (Hutt, 2016).

Because of the high level of security in blockchain technology, it is possible to reduce the corruption and to control the money transactions in different organizations or business sectors (Sharma, 2018). Nowadays, many types of research have demonstrated the use of blockchain technology in different areas, such as healthcare (Gordon and Catalini, 2018), education (Chen et al., 2018), logistics (Dobrovnik et al., 2018), tourism (Önder and Treiblmaier, 2018), etc. In addition, the blockchain is an open and distributed ledger method (Schueffel, 2017). This method provides the various benefits to the government and public administration (Kossow and Dykes, 2018; Ølnes et al., 2017). The UK Government Digital Service is making a blockchain-based digital system for the government activities where distributed ledgers to be at the main part of this system (GOV.UK, 2016). A recent study has displayed the use of Internet of Things (IoT)-based blockchain technology at egovernment in China (Hou, 2017). So we can say that blockchain is an extensive innovative technology of the twenty-first century for government and public administration (Jun, 2018). 
In recent years, some research reports revealed the use of blockchain in public administration for reducing poverty (Schmidt and Sandner, 2017; Kshetri, 2017) and corruption, economic growth, etc. (Oh and Wallsten, 2018). Some blockchain-based modern companies (Tykn, Civic, Factom, Bitfury etc.) believe that the blockchain is a powerful tool for preventing corruption and reducing poverty (Hunink, 2018). So, blockchain is being considered as a tool for sustainable development in the financial, public and environment sectors (Rocamora and Amellina, 2018). Different crypto currencies (Bitcoin, Bytecoin, Litecoin) are working through distributed ledger technology, which is typically a blockchain method (Miraz and Ali, 2018; Olson and Tomek, 2017). Moreover, blockchain applications can be integrated with IoT (Panarello et al., 2018).

What is lacking is a conceptual system architecture or model that can be used to standardize and streamline the use of blockchain for reducing the corruption and poverty so that each researcher or developer in each area does not need to develop his/her own model, but rather focus on his/her particular application area. This paper proposes such a model, with the integration of IoT and price intelligence for monitoring the product or service price.

The rest of the article is organized as follows: the next section describes some recent works and motivation of the research, followed by a section on the theoretical background and methods of this research. Then the research model is described and the proposed system architecture is illustrated, followed by the potential impact of the research. Finally, a brief conclusion is given and some future researches are mentioned.

\section{Literature Review and Research Intentions}

Around 10 years after the civil war, Sierra Leone faced major challenges of weak governance, widespread poverty and systemic corruption, which led to a discussion on the possibilities for ensuring political accountability using blockchain technology (Chohan, 2018). The effects of blockchain are already being observed in the Global South or developing countries. Various other works have proposed the use of blockchain in overcoming economic, social, and political challenges. Blockchain method could help a country in raising transparency, fighting against poverty and reducing financial exclusion (Kshetri, 2017). Smart Contracts technology in blockchain system has been studied as a way to face corruption in governments (Souza, Luciano and Wiedenhöft, 2018). This approach can be utilized in all government payments as a way to enhance the transactions' transparency. Distributed ledger technology (DLT) exhibited a unique advantage to bring greater proficiency and transparency to the interchange of values in the agriculture area (Kamilaris, Prenafeta-Boldú and Fonts, 2018). Benefits and applications of blockchain in agro-foods has been suggested (Tripoli and Schmidhuber, 2018), and a blockchain model for e-agriculture has been presented (Lin et al., 2018). Opportunities, challenges and effects of the blockchain in Africa and India for reducing the poverty and organizational corruption have been discussed (Deloitte Touche Tohmatsu Limited, 2017; Ababa, 2017).

The Internet of Things (IoT) has risen as a set of applications and devices that provide the ability to be used through communication over the Internet. The impacts of IoT for development in Africa have been studied (Ndubuaku and Ndubuaku, 2018). At present, the combination of blockchain and IoT technologies is a significant research topic. The relationship between blockchain and IoT has been suggested, exploring how blockchain can potentially promote the IoT (DeloReyna et al., 2018). Blockchain-based IoT (BIoT) is a new technological framework (Fernández-Caramés and Fraga-Lamas, 2018; Ferrag et al, 2018). Storing the data on blockchain from different IoT devices, and retrieving data is a very important task (Fan et al., 2018). BIoT is expected to be very popular and it is already focusing on crypto currency (Abadi et al, 2018).

There have also been attempts at practical applications using blockchain and price intelligence technologies. Blockchain and big data methods have been employed in pricing and trading energy items through EnergyInternet (Fan, He et al, 2018). Blockchain has also been used with Artificial Intelligence (AI) in healthcare 
(Mamoshina et al, 2018). The impact of price intelligence for combating corruption and monitoring budget in Nigeria has been studied (Aduda, 2007).

Blockchain-based technologies are becoming more advanced, including a blockchain-based database in a cloud computing environment (Gaetani et al., 2017) and blockchain integrated with IoT (QYReports, 2018). IoT technologies are also becoming more advanced; now there is a Cloud of Things (CoT) (Aazam et al., 2014).

The research so far presents ideas, opportunities, challenges and some applications for the use of blockchain method in ameliorating poverty and corruption. However, a standard model of how blockchain could be used in all these application areas is needed. Additionally, BIoT (Blockchain-based IoT / Blockchain IoT) and Price Intelligence are two new technologies that have potential to poverty and corruption. Therefore, this paper demonstrates a BIoT (Blockchain-based IoT) model where different organizations are connected with each other by different cloud servers. Price intelligent technologies are used for monitoring the service and product prices. Money, food, education and medical treatment are major concerns for the poor (Casey et al., 2001), so the proposed blockchain model incorporates banks, healthcare, educational institutes and markets or shops.

\section{Research Model and Methods}

\section{Technologies}

Three technologies have been combined in this paper. These are Blockchain, IoT and Price Intelligence. As demonstrated earlier, Blockchain and IoT have already been used in conjunction and this is called BIoT (Blockchain-based IoT / Blockchain IoT). In order to utilize this method, a P2P (peer-to-peer) network connection is required (Kisembe and Jeberson, 2017) since every one of the users would be keen on connecting to the system. Each node of the system gets two keys: a public key, which is utilized by the customer or consumer for encoding the data to a hub, and a private key, which enables a node to peruse such information (Nisha and Farik, 2017). Hence, two distinctive keys are utilized, one for encoding and another for decoding. The private key is utilized for marking data exchanges through cloud server. Just the customer or consumer with the best possible private key can decode the messages (Eskandari, 2015; Guegan, 2017). Data and information is stored and transferred through the cloud server and product pricing is analyzed using price intelligences so that the system can detect corruption by comparing the prices of services or products. Figure 2 illustrates this combined technology.

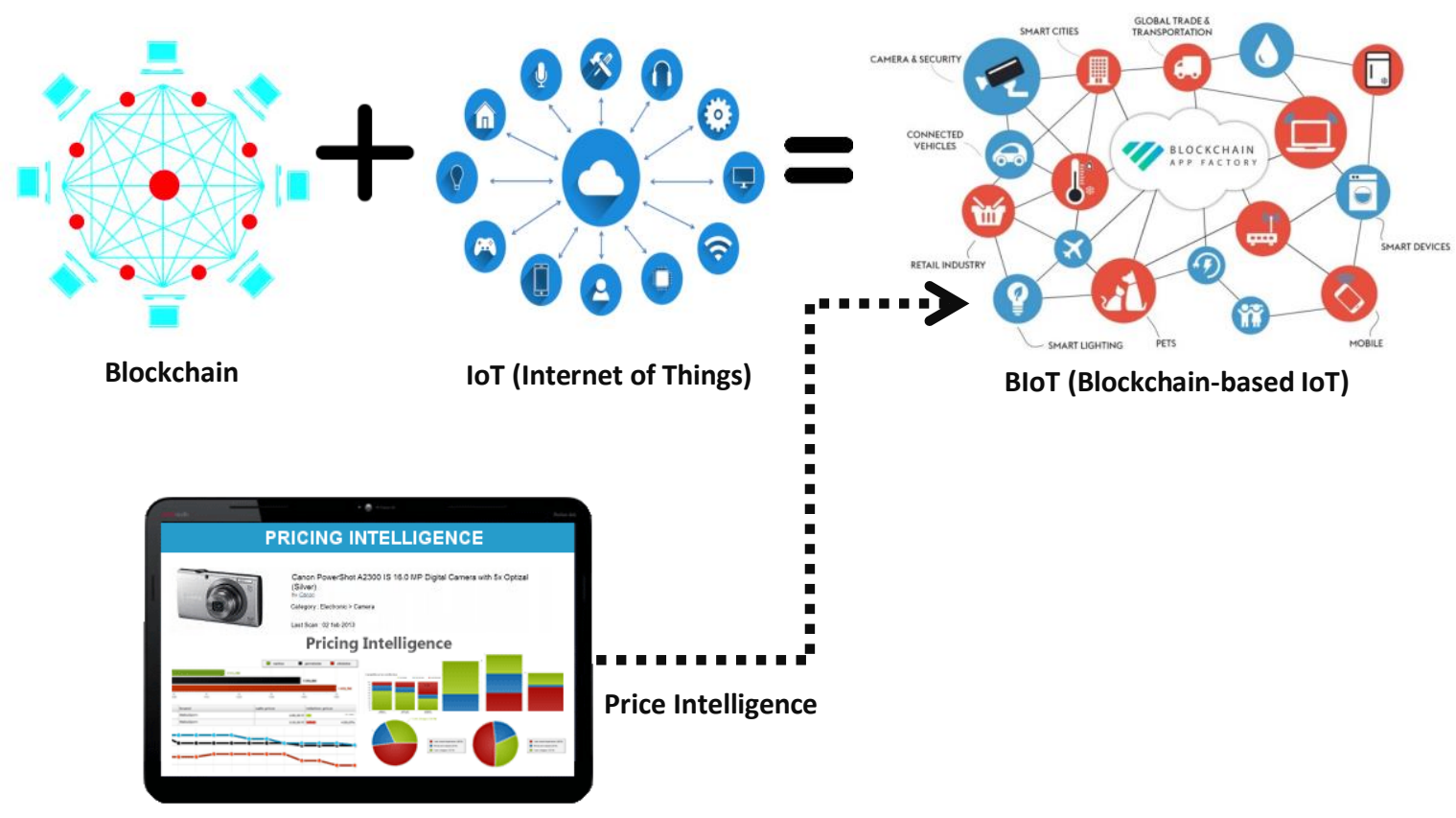


Figure 2: Combined technologies for poverty alleviation

\section{Enterprise Application Integration (EAI)}

Enterprise application integration (EAI) is an integration framework-based methodology (Janssen and Cresswell, 2005) that is utilized for integrating different applications in one system. In this paper, we have integrated banks, healthcare, educational institutions and markets in a BIoT application so that the users have a single point of service for all their needs. Figure 3 illustrates a comprehensive EAI approach, which is being used in this paper's proposed BIoT Model.

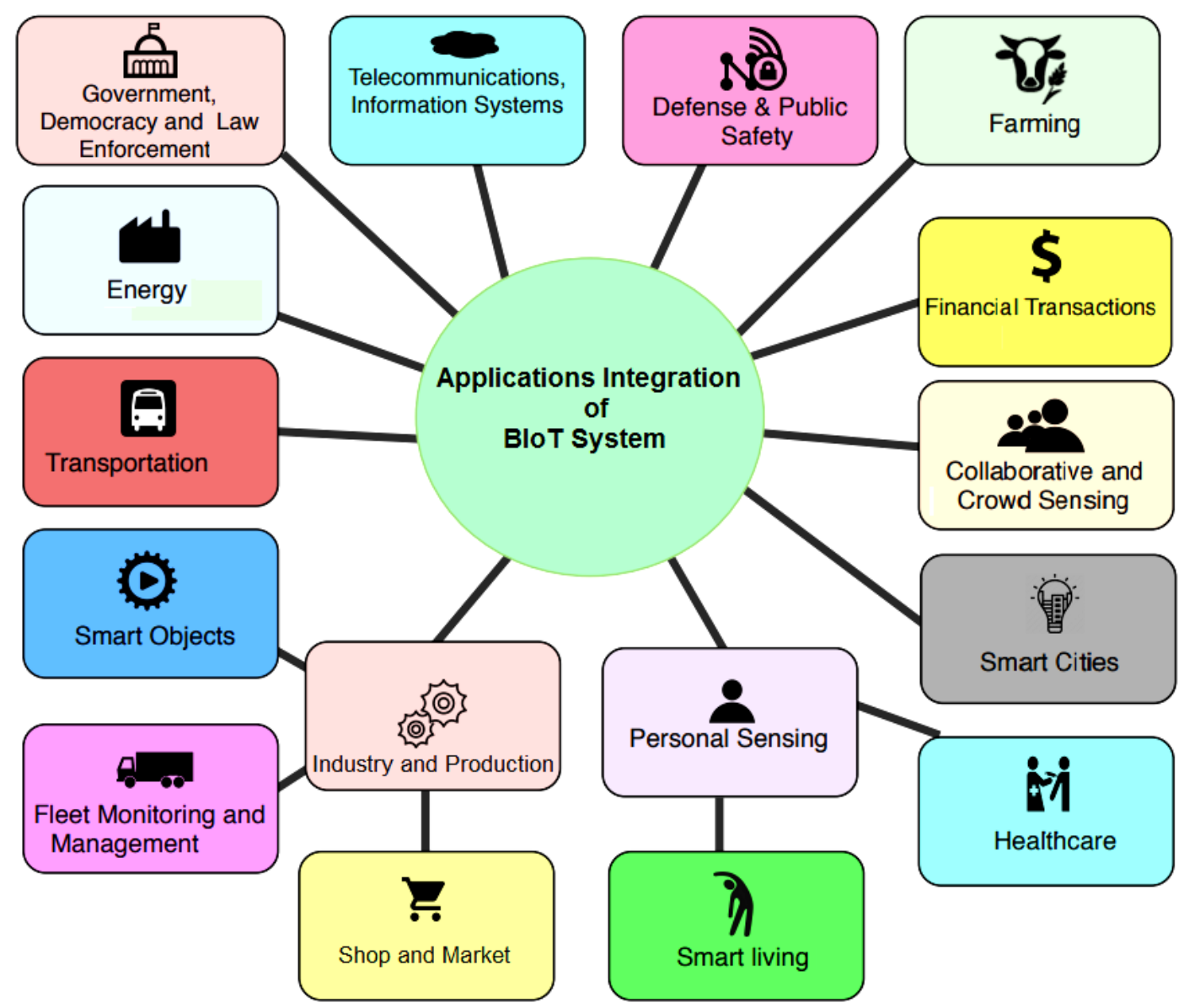

Figure 3: BIoT Integration of different applications.

\section{BIoT Architecture for Price Comparison}

In the proposed model for price comparison to detect and avoid corruption, the customer or consumer and seller or service provider are connected to a cloud server that monitors the prices of products and services. A mid-level P2P (Peer-to-peer) network between mobiles or smart devices uploads invoice price information into the cloud. The steps of the proposed model have been given below:

- Step 1: Consumers buy products or services from sellers or service providers by physical or online money transactions. The original prices of the products and services are stored in cloud server by the producers and sellers.

- Step 2: Price information or invoice is represented as a block in blockchain method which contains the price data. 
- Step 3: The block is broadcasted to every node in the blockchain system through cloud server. Here, the blockchain system contains different nodes. Such as, customer or consumer node, seller or service provider node, retail supplier node, production or manufacture company node, government organization node etc.

- Step 4: The price intelligence method compares between the invoice price and original price. This process occurs in every node of the blockchain system for detecting the price differentiation and corruption. Data verification by nodes is a major part in a blockchain system (Qu et al., 2018; Vo et al., 2018). If the price intelligence method cannot find any comparative price in any node then the block is marked as "confirmed" block. If price intelligence method finds any comparative price in any node then it is marked as "unconfirmed" block and adds the price comparison data.

- Step 5: Generally, in blockchain system cannot add any unverified block, only add the verified block but it can adds confirmed and unconfirmed both blocks (Zamyatin et al., 2018). In our proposed model blockchain system adds confirmed and unconfirmed both blocks. After the verification process (Step 4) blockchain adds the confirmed or unconfirmed blocks.

- Step 6: Finally, the data moves in every node by block in the blockchain system. Unconfirmed block give a notification about the corruption or system monitoring team can visualize the corruption matter by the unconfirmed block's data.

After completing these steps, it is possible to acquire corruption data from the blockchain system. As a result, governments, organizations, companies and the general people can detect price corruption, so that the poor people can save their money. Figure 4 and Figure 5 have represented the above steps. The process of blockchain system is illustrated in Figure 4 and the concept of the proposed model in IoT perspective has been demonstrated in Figure 5.

1 Customer / consumer buy products or take service from seller or service provider.

consumer eller or service provider
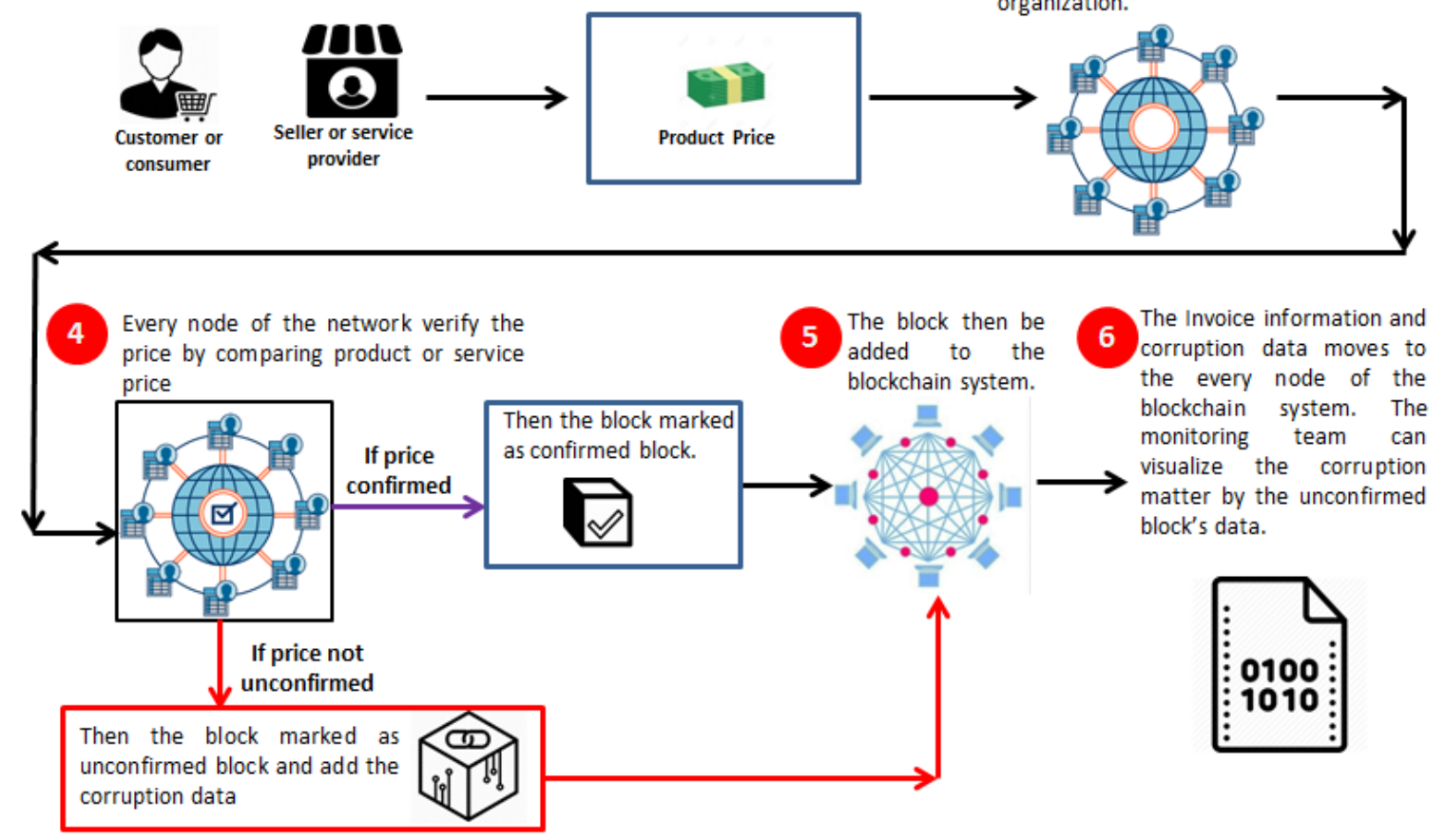

2 Price Information (Invoice) and customer / consumer are represented online as a block.
3 The block is broadcast to every party or node of government and product or service providers' organization. 
Figure 4: Proposed BIoT model for monitoring the price corruption.

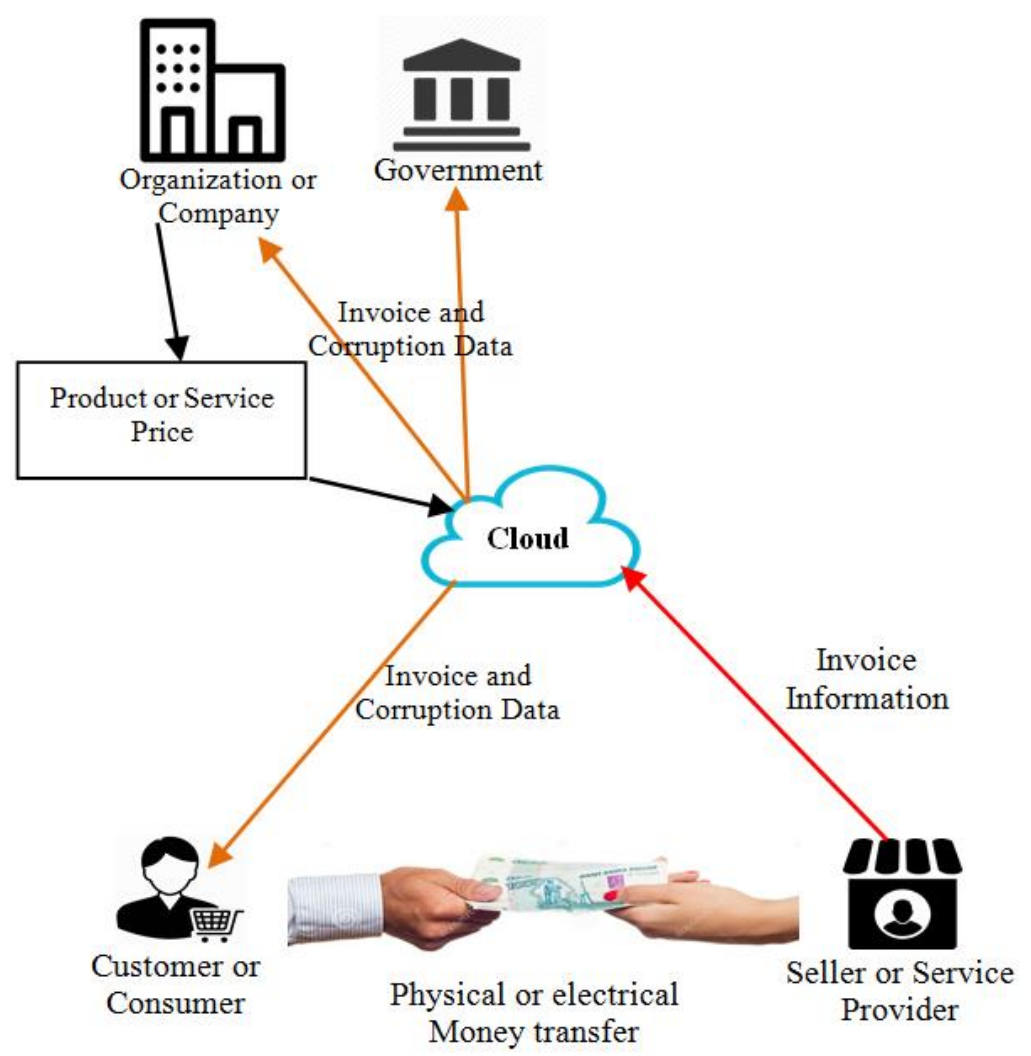

Figure 5: Proposed BIoT model at cloud server based IoT environment.

\section{BIoT Network Architecture}

For applying the proposed method and connected with different organization and company we need a distributed cloud server which is based on blockchain. A recent study demonstrated a blockchain based distributed cloud system which provides secure, low-cost and on-demand access to the most competitive computing infrastructure in an IoT network (Sharma et al, 2017). In our proposed method, different government and non-government organization have been connected with a distributed blockchain based cloud server. Edge devices (Entry Points) of the organization or companies are connected with data storage, applications. This is called Fog Layer (Paul et al, 2018) and different organizations are connected with this fog layer. This layer is maintained under the blockchain based cloud network service. In Figure 6, we have displayed different organizations or companies connected in the cloud server. In this figure, we have also illustrated the overall BIoT network architecture for utilizing and applying our proposed model.

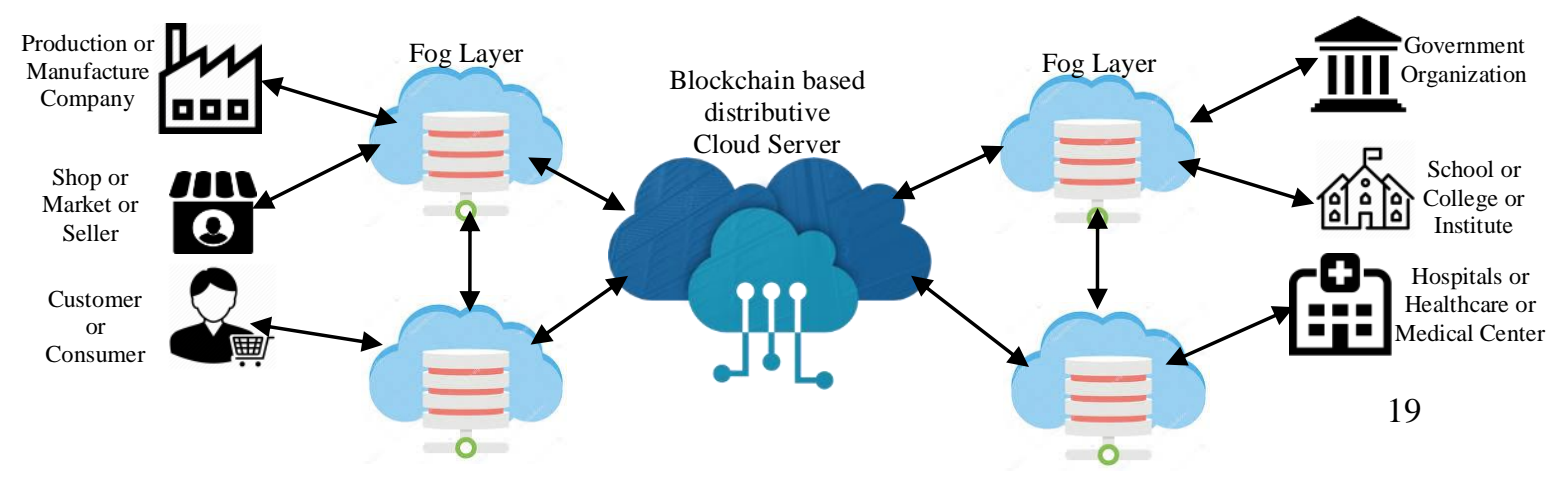



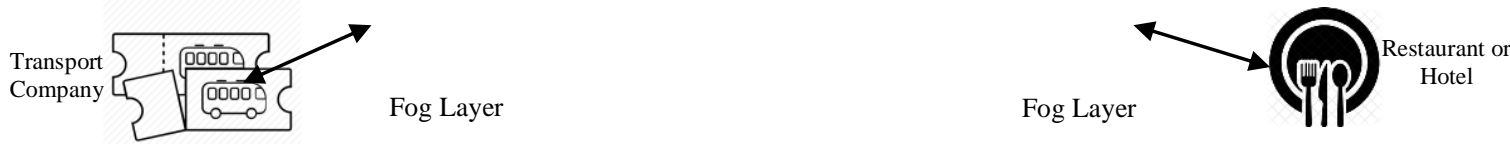

Figure 6: Overall BIoT network architecture for utilizing and applying our proposed model.

\section{Potential Impact}

Price corruption is one of the issues that the world is facing today. Blockchain-based arrangements could be the response to a large number of these issues. After approaching our proposed model for monitoring the price corruption, we have found four hybrid economic business models (García et al., 2002). They are C2B2B (Consumer-to-Business-to-Business), C2B2G (Consumer-to-Business-to-Government), B2B2G (Business-toBusiness-to-Government) and C2G2B (Consumer-to- Government-to-Business). These four hybrid models are essential for following our proposed method. The perspectives of these four hybrid business models in our proposed BIoT system are given below and also illustrated in Figure 7.

- C2B2G (Consumer-to-Business-to-Government): When a consumer purchases a product or receives services from an organization or company, this organization or company is connected with the government of our BIOT system. VAT and Tax issues have been involved in this connection.

- C2B2B (Consumer-to-Business-to-Business): On the other hand, when a consumer purchases a product or receives services from a shop or third party service provider (hospital, local bank etc.), this shop or third party service provider is also connected with another business organization.

- B2B2G (Business-to-Business-to-Government): Government sections are always connected with B2B connection for monitoring root level price corruption. VAT and Tax issues have also been involved in this connection.

- C2G2B (Consumer-to- Government-to-Business): In our BIoT system, every consumer is always connected with government. When a consumer purchases or receives services from a government organization (government hospital, government bank etc.), these organizations are connected with another business organizations for transferring money.
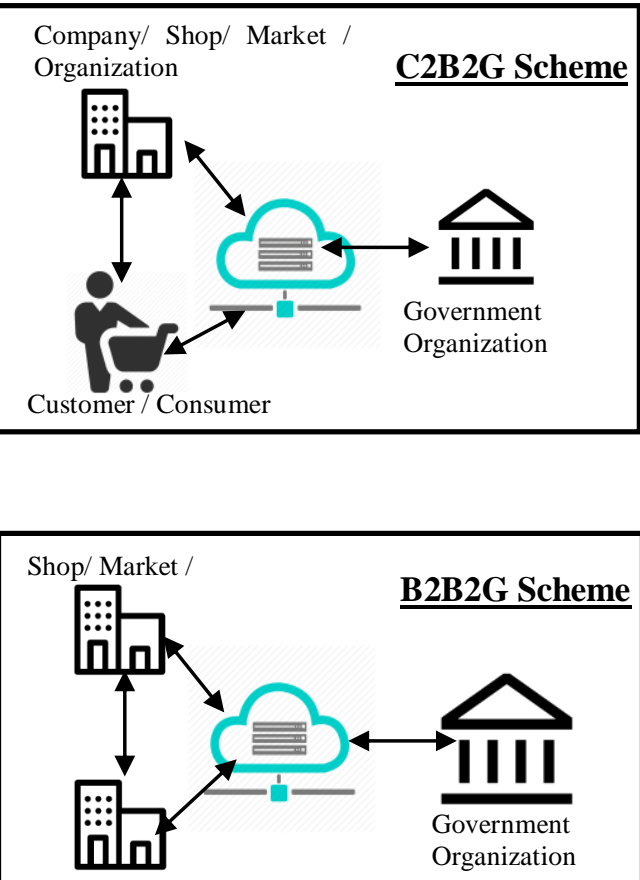

20
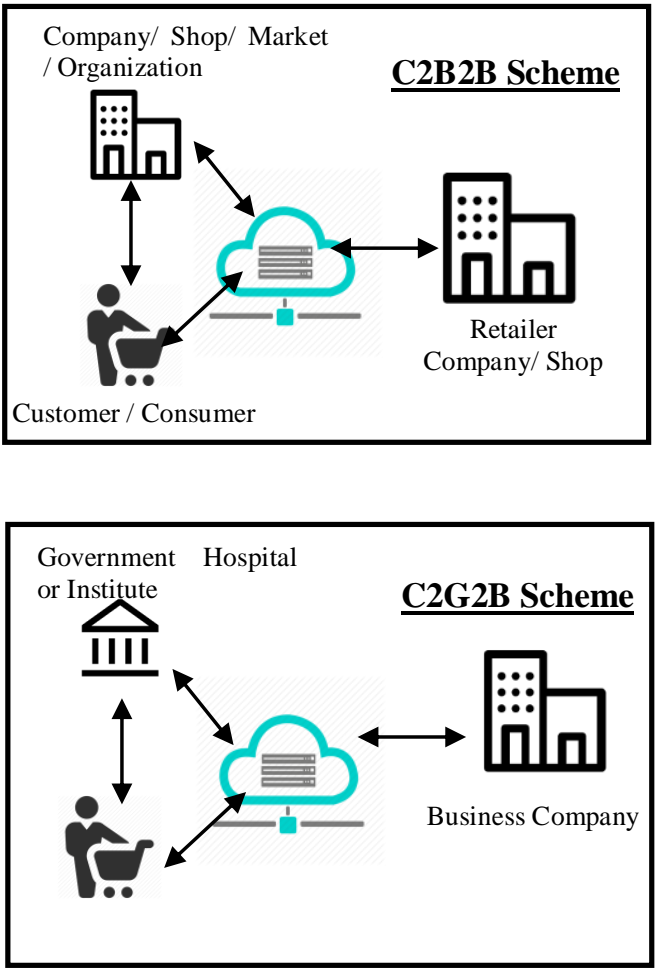
Retailer
Company/ Shop
Customer / Consumer

Figure 7: Different business model in our BIoT system.

After viewing the above hybrid business models, we have realized that distributive blockchain can add different business methods for monitoring the price corruption issues in different sectors. So we can say that, Entrepreneurial Orientation and Business Financial Performance (Nyello et al., 2002) are very important terms for reducing the poverty through decreasing the price corruption issue.

\section{Conclusion and Future Work}

Blockchain applications are in an early phase of development. In principle, there are numerous possible uses of the blockchain technology and other new innovations through which the poor people may be benefited. Besides that our research is based on sustainable development. Our study includes a few more shortcomings of blockchain technology in reduction of price corruption and its impacts of poverty. Proposed BIoT model has an important limitation especially when it comes to evaluate hybrid business model (C2B2B, C2B2G, B2B2G and $\mathrm{C} 2 \mathrm{G} 2 \mathrm{~B}$ ) conditions in real life, such as user access, node verification, data exchange etc. In practice, however, a number of challenges and difficulties stand in the way of implementation and practical results of our proposed model. In our forthcoming research we will demonstrate these limitations and challenging matters. Moreover, the study is gives a technological design of blockchain technology in price corruption area. Finally, we must not forget the poverty issue. The research illustrates an indication to BIoT model which represents how blockchain based technology can reduce the price corruption and helps for reducing poverty.

This concept of proposed model is currently under experiment in the perspective of healthcare or medical section. These are key examination for better comprehension about Eelectronic Medical Record (EMR) in our future exercises. All the BIoT can be changed into a scholarly model by various learning calculations. In our forthcoming exploration, we are hopeful to complete a real-world test with Eelectronic Medical Record (EMR) and Hospital Information System with our own deployed application.

\section{References}

Dimant, E., and Tosato, G., 2017, Causes and Effects of Corruption: What has Past Decade's Empirical Research Taught us? A Survey. Journal of Economic Surveys, 32(2), 335-356

Unver, M., and Koyuncu, J. Y., 2016, The Impact of Poverty on Corruption. Journal of Economics Library, $4(3), 632-642$.

Yunan, Z. Y., and Andini, A., 2018, Corruption, Poverty, and Economic Growth (Causality Studies among Asean Countries). Journal of Economics and Policy, 11(2), 413-428.

Awojobi, and Nathaniel, O., 2014, Corruption and Underdevelopment in Africa A Discourse Approach. International Journal of Economics, Commerce and Management, 2(10).

Zheng, Y., and Liao, X., 2018, The Formation Mechanism and Precision Control of Corruption in Poverty Alleviation from the Perspective of System Dynamics. Mathematical Problems in Engineering, 2018, article ID 2796146, 1-10.

Dubey, A., and Tiwari, S., 2018, Economic Growth and Urban Poverty in India. Environment and Urbanization Asia, 9(1), 1-19.

Andrade, L., Flégl, M., and Jiménez-Bandala, C. A., 2018. Effect of corruption and poverty on efficient education in Latin America. Proceedings of the 15th International Conference on Efficiency and Responsibility in Education, Prague, Czech Republic, June, pp. 7-13.

Omoniyi, B. B., 2018, An examination of the causes of poverty on economic growth in Nigeria. Africa's Public Service Delivery and Performance Review, 6(1), pp. 1-10. 
Palvia, P., Baqir, N., Nemati, H., 2018, ICT for socio-economic development: A citizens' perspective. Information \& Management, 55(2), pp. 160-176.

Katz, R. L., 2017, Discussion paper on social and economic impact of digital transformation on the economy. GSR-17 Reports and papers, International Telecommunication Union (ITU).

Food and Agriculture Organization (FAO) of The United Nations, 2018, Tackling poverty and hunger through digital innovation.

Phillip, A., Chan, J. S.K., and Peiris, S., 2017, A new look at Cryptocurrencies. Economics Letters, 163, 6-9.

Third, A., Quick, K., Bachler, M., and Domingue, J., 2018, Government services and digital identity. Knowledge Media Institute, The Open University, European Union Blockchain Observatory and Forum.

Jalakas, P., 2018, Blockchain from Public Administration Perspective: Case of Estonia. Master's Thesis, School of Business and Governance, Ragnar Nurkse Department of Innovation and Governance, Tallinn University of Technology.

Kim, K., and Kang, T., 2017, Does Technology Against Corruption Always Lead to Benefit? The Potential Risks and Challenges of the Blockchain Technology. 2017 OECD Global Anti-Corruption and Integrity Forum.

Risius, M., and Spohrer, K., 2017, A Blockchain Research Framework: What We (don't) Know, Where We Go from Here, and How We Will Get There. Business \& Information Systems Engineering, 59(6), pp. 385-409.

Mendling, J., et al., 2018, Blockchains for Business Process Management - Challenges and Opportunities. ACM Transactions on Management Information Systems, 9(1), article no. 4.

Santiso, C., 2018, Will Blockchain Disrupt Government Corruption?. Stanford Social Innovation Review (SSIR), 5 March 2018, Link: https://ssir.org/articles/entry/will_blockchain_disrupt_government_corruption

Gupta, S., and Sadoghi, M., 2018, Blockchain Transaction Processing. edited by Sakr, S., Zomaya, A. Encyclopedia of Big Data Technologies (Cham: Springer).

Hutt, R., 2016, All you need to know about blockchain, explained simply. World Economic Forum, Link: https://www.weforum.org/agenda/2016/06/blockchain-explained-simply/

Sharma, T. K., 2018, How can blockchain reduce corruption?. Blockchain Council, 14 February 2018, Link: https://www.blockchain-council.org/blockchain/how-can-blockchain-reduce-corruption/

Gordon, J. W., and Catalini, C., 2018, Blockchain Technology for Healthcare: Facilitating the Transition to Patient-Driven Interoperability. Computational and Structural Biotechnology Journal, 16, pp. 224-230.

Chen, G., Xu, B., Lu, M., and Chen, N., 2018, Exploring blockchain technology and itspotential applications for education. Smart Learning Environments, 5(1), article no. 1, pp. 1-10.

Dobrovnik, M., Herold, D. M., Fürst, E., and Kumme, S., 2018, Blockchain for and in Logistics: What to Adopt and Where to Start. Logistics, 2(18), article: 18, pp. 1-14.

Önder, I., and Treiblmaier, H., 2018, Blockchain and tourism: Three research propositions. Annals of Tourism Research, 72, pp. 180-182.

Schueffel, P., 2017, Alternative Distributed Ledger Technologies Blockchain vs. Tangle vs. Hashgraph - A High-Level Overview and Comparison. SSRN Electronic Journal. DOI: http://dx.doi.org/10.2139/ssrn.3144241

Dobrovnik, M., Herold, D. M., Fürst, E., and Kumme, S., 2018, Blockchain for and in Logistics: What to Adopt and Where to Start. Logistics, 2(18), article no. 18, pp. 1-14.

Kossow, N., and Dykes, V., 2018, Beyond the Hype: Distributed ledger technology in the field of public administration. Hertie School of Governance.

Ølnes, S., Ubacht, J., and Janssen, M., 2017, Blockchain in government: Benefits and implications of distributed ledger technology for information sharing. Government Information Quarterly, 34(3), pp. 355-364.

GOV.UK, Government Office for Science, Distributed ledger technology: beyond block chain, 2016, A report by the UK Government Chief Scientific Adviser.

Hou, H., 2017. The Application of Blockchain Technology in E-government in China. Proceedings of 2017 26th International Conference on Computer Communication and Networks (ICCCN), Vancouver, BC, Canada, JulyAug.

Jun, M., 2018, Blockchain government - a next form of infrastructure for the twenty-first century. Journal of Open Innovation: Technology, Market, and Complexity, 4(1), article no. 7, pp. 2-12. 
Schmidt, K., and Sandner, P., 2017, Solving Challenges in Developing Countries with Blockchain Technology. FSBC Working Paper. Frankfurt School Blockchain Center.

Oh, S., and Wallsten, S., 2018, Is Blockchain Hype, Revolutionary, or Both? What We Need to Know. Technology Policy Institute.

Kshetri, N., 2017, Will blockchain emerge as a tool to break the poverty chain in the Global South?. Third World Quarterly, 38(8), pp. 1710-1732.

Hunink, Y., 2018, Blockchain for Change. The Spindle.

Rocamora, A. R., and Amellina, A., 2018, Blockchain Applications and the Sustainable Development Goals Analysis of blockchain technology's potential in creating a sustainable future. Institute for Global Environmental Strategies (IGES). DOI: 10.13140/RG.2.2.15469.03044

Miraz, M. H., and Ali, M., 2018, Applications of Blockchain Technology beyond Cryptocurrency. Annals of Emerging Technologies in Computing, 2(1), pp. 1-6.

Olson, E., and Tomek, J., 2017, Cryptocurrency and the BlockChain: Technical Overview and Potential Impact on Commercial Child Sexual Exploitation. International Centre for Missing \& Exploited Children (ICMEC).

Panarello, A., Tapas, N., Merlino, G., Longo, F., and Puliafito, A., 2018, Blockchain and IoT Integration: A Systematic Survey. Sensors, 18(8), article: 2575, pp. 1-37.

Chohan, Usman W., 2018, Blockchain Enhancing Political Accountability? Sierra Leone 2018 Case. SSRN. DOI: http://dx.doi.org/10.2139/ssrn.3147006

Kshetri, N., 2017, Potential roles of blockchain in fighting poverty and reducing financial exclusion in the global south. Journal of Global Information Technology Management, 20(4), pp. 201-204.

Souza, R. C., Luciano, E. M., and Wiedenhöft, G. C., 2018. The uses of the Blockchain Smart Contracts to reduce the levels of corruption: Some preliminary thoughts. Proceedings of the 19th Annual International Conference on Digital Government Research: Governance in the Data Age Delft, Netherlands, May-June, article no. 110.

Kamilaris, A., Prenafeta-Boldú, F. X., and Fonts, A., 2018, The Rise of the Blockchain Technology in Agriculture. ICT Update, Issue: 18, pp. 18-19.

Tripoli, M., and Schmidhuber, J., 2018, Emerging Opportunities for the Application of Blockchain in the Agrifood Industry. Food and Agriculture Organization (FAO) of The United Nations. International Centre for Trade and Sustainable Development (ICTSD).

Lin, Y., Petway, J. R., Anthony, J., Mukhtar, H., Liao, S., Chou, C., and Ho, Y., 2017, Blockchain: The Evolutionary Next Step for ICT E-Agriculture. Environments, 4(3), article no. 50, pp. 1-13.

Deloitte Touche Tohmatsu Limited, Blockchain technology in India Opportunities and challenges, 2017.

Ababa, A., 2018, Blockchain Technology in Africa. Food and Agriculture Organization (FAO) of The United Nations. United Nations Economic Commission for Africa.

Ndubuaku, M., and Okereafor, D. T., 2015. Internet of Things for Africa: Challenges and Opportunities. Proceedings of the 2015 International Conference on Cyberspace Governance- CYBERAbuja 2015, Abuja, Federal Capital Territory, Nigeria, November, pp. 23-31.

Reyna, A., Martín, C., Chen, J., Soler, E., and Diaz, M., 2018, On blockchain and its integration with IoT. Challenges and opportunities. Future Generation Computer Systems, 88, pp. 173-190.

Fernández-Caramés, T. M., Fraga-Lamas, P., 2018, A Review on the Use of Blockchain for the Internet of Things. Privacy-preservation, arXiv:1806.09099v1 [cs.CR] 24 Jun 2018.

Fan, L., Gil-Garcia, J. R., Werthmuller, D., Burke, G. B., and Hong, X., 2018. Investigating blockchain as a data management tool for IoT devices in smart city initiatives. Proceedings of the 19th Annual International Conference on Digital Government Research: Governance in the Data Age, Delft, The Netherlands, May-June, article no. 100.

Abadi, A., Ellul, J., Azzopardi, G., 2018. The Blockchain of Things, Beyond Bitcoin: A Systematic Review. Proceedings of the IEEE, BIoT 2018: The 1st International Workshop on Blockchain for the Internet of Things, Halifax, Canada, July. 
Fan, T., He, Q., Nie, E., and Chen, S., 2018. A study of pricing and trading model of Blockchain \& Big databased Energy-Internet electricity. ESMA 2017, IOP Conf. Series: Earth and Environmental Science, 108(4), article no. 052083, pp. 1-12.

Mamoshina, P., Ojomoko, L., Yanovich, Y., et al., 2018. Converging blockchain and next-generation artificial intelligence technologies to decentralize and accelerate biomedical research and healthcare. Oncotarget, 9(5), pp. 5665-5690.

Adudu, G. T., 2007, Budget monitoring and Price Intelligence Unit (due process): A mechanism for combating corruption in infrastructure delivery in Nigeria. Case study. Partnering to Combat Corruption series, WEDC, Loughborough University, UK, ISBN: 978-1-84380-122-1

Gaetani, E., et al., 2017. Blockchain-based Database to Ensure Data Integrity in Cloud Computing Environments. Proceedings of the First Italian Conference on Cybersecurity (ITASEC17), Venice, Italy, CEUR Workshop Proceedings, 1816, pp. 146-155.

QYReports, Global Blockchain Internet Of Things (BIOT) Market Forecast 2018 - 2025, 2018, Link: http://www.qyreports.com/report/global-blockchain-internet-of-things-biot-market-forecast-2018-2025-101376/

Aazam, M., Khan, I., Alsaffar, A. A., Huh, E., 2014. Cloud of Things: Integrating Internet of Things and cloud computing and the issues involved. Proceedings of 2014 11th International Bhurban Conference on Applied Sciences \& Technology (IBCAST) Islamabad, Pakistan, January, pp. 414-419.

Casey, P. H., Szeto, K., Lensing, S., Bogle, M., and Weber, J., 2001, Children in food-insufficient, low-income families: prevalence, health, and nutrition status. Archives of Pediatrics and Adolescent Medicine, 155(4), pp. 508-514.

Kisembe, P., and Jeberson, W., 2017, Future of Peer-To-Peer Technology with the Rise of Cloud Computing. International Journal of Peer to Peer Networks (IJP2P), 8(2/3), pp. 45-54.

Nisha, S., and Farik, M., 2017, RSA Public Key Cryptography Algorithm - A Review. International Journal of Scientific \& Technology Research, 6(7), pp. 187-191.

Eskandari, S., Barrera, D., Stobert, E., and Clark, J., 2015, A first look at the usability of bitcoin key management. CoRR, abs/1802.04351.

Guegan, D., 2017, Public Blockchain versus Private blockhain. Documents de travail du Centre d'Economie de la Sorbonne 2017.20 - ISSN : 1955-611X, HAL Id: halshs-01524440

Janssen, M., and Cresswell, A. M., 2005, An enterprise application integration methodology for e-government. Journal of Enterprise Information Management, 18(5), pp. 531-547.

Qu, C., Tao, M., Zhang, J., Hong, X., and Yuan, R., 2018, Blockchain Based Credibility Verification Method for IoT Entities. Security and Communication Networks, 2018, Article ID 7817614.

Vo, H. T., Kundu, A., and Mohania, M., 2018, Research Directions in Blockchain Data Management and Analytics. OpenProceedings, EDBT 2018, pp. 445-448.

Zamyatin, A., Stifter, N., Schindler, P., Weippl, E., and Knottenbelt, W. J., 2018, Flux: Revisiting Near Blocks for Proof-of-Work Blockchains. Cryptology ePrint Archive, 2018, 415.

Reyna, A., Martín, C., Chen, J., Soler, E., Díaz, M., 2018, On blockchain and its integration with IoT. Challenges and opportunities. Future Generation Computer Systems, 8(2018), pp. 173-190.

Fernández-Caramés, T. M., and Fraga-Lamas, P., 2018, A Review on the Use of Blockchain for the Internet of Things. IEEE Access, 6, pp. 32979-33001.

Sharma, P. K., Chen, M., Park, and J. H., 2017, A Software Defined Fog Node based Distributed Blockchain Cloud Architecture for IoT. IEEE Access, 8, pp. 115-124.

Paul, A., Pinjari, H., Hong, W., Seo, H. C., and Rho, S., 2018, Fog Computing-Based IoT for Health Monitoring System. Journal of Sensors, 2018.

García, F. J., Gil, A. B., Moreno, M. N., Hernández, J. A., 2002, A B2B/B2C Hybrid E-Commerce Model. GRIAL repository, Proceedings of 1st International Workshop on Practical Applications of Agents and Multiagent Systems Proceedings, IWPAAMS'2002, Salamanca, Spain, October, 165-172. ISBN 84-932864-2-7.

Nyello, R. M., Chalu, H., Kitindi, E., 2018, Financial Innovation, Entrepreneurial Orientation and Business Financial Performance: The Case of Micro Businesses in Tanzania. ORSEA Journal, 8(1), pp. 33-49. 